\title{
Muße und Gesellschaft
}

\author{
Hrsg. v. Gregor Dobler u. Peter Philipp Riedl
}

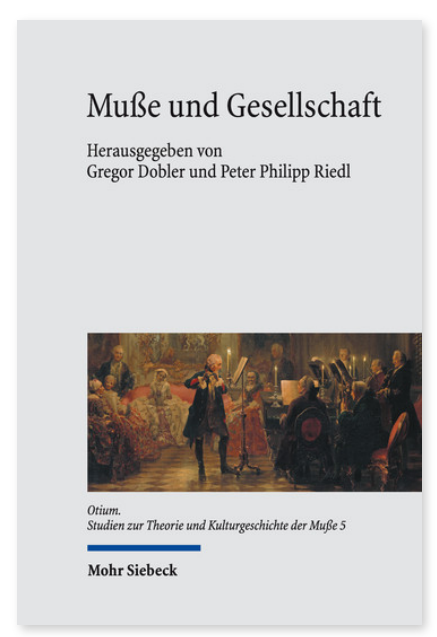

2017. VII, 418 Seiten. Otium 5

ISBN 978-3-16-155566-4 eBook PDF

ISBN 978-3-16-155156-7

Festeinband $84,00 €$

Muße ist ein freies Verweilen in der Zeit jenseits von Zweckrationalismus und Utilitarismus. Sie zielt auf Freiheit von Zeitzwängen und unmittelbarer Leistungserwartung, auf ästhetisch und räumlich inszenierte Lebensformen einer Freiheit, die in der Zeit nicht der Herrschaft der Zeit unterliegt. Muße mag damit zunächst als individuelle Erfahrung und Haltung erscheinen, die den Menschen aus gesellschaftlichen Zwängen herausnimmt, aber sie ist auch ein eminent soziales Phänomen. Die Chancen, erfolgreich Räume der Muße für sich zu beanspruchen, sind höchst ungleich verteilt. Der Freiraum zur Muße wird häufig zum nach außen verteidigten Merkmal einer gesellschaftlichen Rolle. Der vorliegende Band, der 17 Aufsätze aus zehn verschiedenen Disziplinen versammelt, beleuchtet die gesellschaftliche Dimension von Muße in unterschiedlichen historischen und kulturellen Kontexten und verdeutlicht ihr symbolisches Kapital in seinen jeweiligen Ausprägungen.

Inhaltsübersicht

Gregor Dobler/Peter Philipp Riedl: Einleitung

\section{Muße und Arbeit}

Hans Bertram: Lebenszeit und Alltagszeit. Auf der Suche nach der verloren gegangenen Balance von Muße, Arbeit und Fürsorge im Lebenslauf - Jochen Gimmel: Mußevolle Arbeit oder ruheloser Müßiggang - Gregor Dobler: Arbeit, Arbeitslosigkeit und Rhythmus

\section{Kulturelle Codierung und Lebensformen}

Joachim Bauer: Selbststeuerung als Voraussetzung von Muße - Linus Möllenbrink: »inter negocia literas et cum literis negocia in usu habere«. Die Verbindung von vita activa und vita contemplativa im Pirckheimer-Brief Ulrichs von Hutten (1518) Caroline Emmelius: Muße - Müßiggang - Nichtsnutzigkeit. Zum Verhältnis von Muße und Arbeit in Morus' Utopia, im Ulenspiegel und im Lalebuch - Monika Fludernik: Muße als soziale Distinktion - Simone Müller: Der 'hohe Müßiggänger' (kōtō yūmin ) im sozial-politischen Diskurs der japanischen Moderne - Alexander Lenger: Die Geisteswissenschaften und ihre Muße. Das akademische Feld zwischen Kreativitätsimperativ und Zweckrationalität

\section{Ästhetische Erfahrung und Bildung}

Stefan Matuschek: Muße und Spiel. Schillers Wende von der freien zur befreienden Kunst - Peter Philipp Riedl: Rastlosigkeit und Reflexion. Zum Verhältnis von vita activa und vita contemplativa in Goethes Festspiel Pandora (1808) - Elisabeth Cheauré: Faulheit. Muße. Kreativität. Überlegungen zur Oblomowerei

\section{Freiraum und Institutionalisierung}

Burkhard Hasebrink: Otium contemplationis . Zu einer Begründungsfigur von Autorschaft im Legatus divinae pietatis Gertruds von Helfta - Albert Schirrmeister: Die gute und die schlechte Zeit der Muße. Funktionalisierungen von oisiveté zur Zeit Ludwigs XIV. - Jochen Gimmel: Vom Fluch der Arbeit und vom Segen des Sabbats. Überlegungen zu einer alternativen Traditionslinie der Muße

\section{Muße und Gender}

Bastian Schlüter: 'Mein Schreibetisch'. Muße erfahren, schreiben, lesen bei Sophie von La Roche - Elisabeth Cheauré: Muße, Gender - und ein Selbstmord. Zur Funktion von Handarbeiten in L.N. Tolstojs Anna Karenina

Gregor Dobler ist Professor für Ethnologie an der Universität Freiburg und Sprecher des SFB 1015 »Muße. Grenzen Raumzeitlichkeit, Praktiken".

https://orcid.org/0000-0001-6598-1709

Peter Philipp Riedl Geboren 1965; Studium der Germanistik und Geschichte; 1995 Promotion; 2002 Habilitation; Visiting Fellow am Trinity College, Cambridge, UK; seit 2012 apl. Professor für Neuere deutsche Literaturgeschichte an der AlbertLudwigs-Universität Freiburg.

https://orcid.org/0000-0002-7908-9292

Jetzt bestellen:

https://mohrsiebeck.com/buch/musse-und-gesellschaft-9783161555664?no_cache=1

order@mohrsiebeck.com

Telefon: $+49(0) 7071-923-17$

Telefax: +49 (0)7071-51104 